\title{
ДО ПРОБЛЕМИ ВИЗНАЧЕННЯ ЗАЛИШКОВОЇ МІЦНОСТІ БАЛОК, ПОШКОДЖЕНИХ ТРІЩИНАМИ
}

\section{TO THE PROBLEM OF DETERMINATION OF THE RESIDUAL STRENGTH OF BEAMS, DAMAGED BY CRACKS}

Шваб’юк В.І., д.т.н., проф., Ротко С.В., к.т.н., доц., Шваб'юк В.В., к.т.н., доц., Ужегова О.А., к.т.н., доц., Кислюк Д.Я., к.т.н., доц. (Луцький національний технічний університет)

Shvabyuk V.I., Doctor of Engineering, Professor, Rotko S.V., Ph.D, Associate Professor, Shvabyuk V.V., Ph.D., Associate Professor, Uzhehova O.A., Ph.D., Associate Professor, Kyslyuk D.Y., Ph.D., Associate Professor (Lutsk National Technical University, Lutsk)

Анотація. У роботі розроблена методологія визначення залишкової міџності композитних балок, пошкоджених крайовою тріщиною в області діi розтягувальних напружень. Для проведення таких розрахунків використовується некласична модель згину композитних балок, котра враховує вплив деформачій поперечного зсуву та обтиснення. Для композитної балки, навантаженої розподіленим навантаженням і пошкодженої невеликою крайовою тріщиною у нижній поверхні балки, де діють розтягувальні напруження, одержані формули для граничних навантажень. Наведено приклад числових результатів для різних товщин і матеріалів. Зроблено аналіз отриманих результатів.

Summary. The evaluation of the residual strength of structures already damaged by cracks is an extremely important scientific problem today. This is due to the fact that during prolonged use in the elements of the structure cracks appear both from the fatigue of the material and from the presence of certain stress concentrators in their design. As a result, the initial design strength, which did not take into account the presence of cracks, begins to decline significantly. In order to avoid the destruction of such a structure, a corresponding reduction in the design load is required.

The problem of determining the stress-strain state of an anisotropic beam with an inclined crack, in the formulation of a flat problem of the theory of elasticity, is considered by S. Serensen and G. Zaitsev in a well-known work [1]. The problems of isotropic strip with a transverse and a longitudinal crack using the linear conjugation method are solved in the writings of V. Panasyuk, B. Lozovyi and other authors [2,3,4,5]. Authors G. Kit, O. Sushko and B. Lozovyi [6] considered bending of strips of rectangular or elliptical sections, which are damaged inside by a circular crack, with a different load. The stress-strain state in the vicinity of cracks was investigated in this work as well as dependence of SIF (stress intensity factor) from the load and location of the crack. The method of boundary integral equations with complex potentials by M. Mushelishvili was used. In another paper [7], the authors investigate the net bending of a beam with a 
crack, taking into account the plastic zones near its vertices, where an analytic solution is obtained in the class of functions restricted to the ends of the plastic strips.

The methodology for determining the residual strength of composite beams damaged by the edge crack in the area of tensile stress is developed. Such calculations use a non-classical bending model of composite beams, which takes into account the effect of shear and compression deformations. Formulas for the limit loads of a composite beam, which is loaded by a distributed load and damaged by a small boundary crack at the lower surface of the beam, have been obtained. Numerical results for different thicknesses and materials are given.The results obtained are analyzed and compared with the results for the beams without damage.

Ключові слова: тріщина, поперечна анізотропія, залишкова міцність.

Keywords: crack, transverse anisotropy, residual strength.

Вступ. Оцінка залишкової міцності конструкцій, що вже пошкоджені дефектами типу тріщин, є на сьогодні надзвичайно важливою науковою проблемою. Це пов'язано з тим, що за час тривалої експлуатації в елементах конструкцій тріщини з'являються як від утоми матеріалу, так i від наявності в їх конструкції певних концентраторів напружень. У результаті початкова розрахункова міцність, яка не враховувала наявності тріщин, починає значно знижуватися. Для уникнення руйнування такої конструкції необхідне відповідне зниження розрахункового навантаження.

Аналіз літературних джерел. Проблема визначення напруженодеформованого стану анізотропної балки із нахиленою тріщиною, у постановці плоскої задачі теорії пружності, розглянута С.В. Серенсеном та Г.П. Зайцевим у відомій роботі [1]. У працях В.В. Панасюка, Б.Л. Лозового та інших авторів $[2,3,4,5]$, із використанням методу лінійного спряження, розв'язуються задачі для ізотропної смуги з поперечною та поздовжньою тріщиною. Авторами Г.С. Кітом, О.П. Сушком та Б.Л. Лозовим [6] розглядався згин різним навантаженням смуг прямокутного або еліптичного перерізів, що пошкоджені всередині круговою тріщиною. У даній роботі методом граничних інтегральних рівнянь, із використанням комплексних потенціалів М.I. Мусхелішвілі, досліджено напруженодеформований стан в околі цих тріщин та залежність КІН від навантаження та розташування тріщини. Ще в одній роботі [7] авторами досліджується чистий згин балки 3 тріщиною з урахуванням пластичних зон біля iï вершин, де отримано аналітичний розв'язок у класі функцій обмежених на кінцях пластичних смуг.

У даній роботі за допомогою рівнянь некласичної моделі згину коротких балок досліджено вплив на залишкову міцність наявних у балках пошкоджень типу тріщин і поперечної анізотропії матеріалу в порівнянні 3 результатами для балок без пошкоджень. 
Постановка задачі. Розглядається композитна балка, пошкоджена невеликою крайовою тріщиною у нижній поверхні балки, де діють розтягувальні напруження. Балка навантажена розподіленим навантаженням (рис. 1).

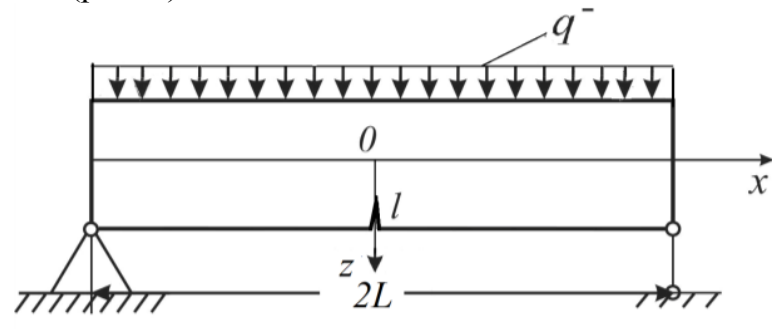

Рис. 1. Схема навантаження балки

Виклад основного матеріалу. Визначальним рівнянням некласичної моделі $\epsilon$ рівняння [4] :

$$
\frac{d^{4} w}{d x^{4}}=\frac{q_{2}}{E I}-\frac{\varepsilon_{1} h^{2}}{E I} \cdot \frac{d^{2} q_{2}}{d x^{2}}-\frac{\varepsilon_{2} h^{4}}{4 E^{\prime} I} \frac{d^{4} q_{2}}{d x^{4}},
$$

де $I=\frac{2}{3} t h^{3} ; q_{1}=\frac{1}{2}\left(q^{+}-q^{-}\right) ; q_{2}=q^{+}+q^{-}$;

$\varepsilon_{1}=\frac{1}{10}\left(4 \frac{E}{G^{\prime}}-3 v^{\prime \prime}\right) ; \quad \varepsilon_{2}=\frac{1}{5}\left(1-v^{\prime \prime} \frac{G^{\prime}}{E}\right) ;$

$q^{ \pm}$- розподілене навантаження зовнішніх $(z= \pm h)$ граней балки; $E, E^{\prime}, G^{\prime}, v^{\prime \prime}$-модулі пружності та коефіцієнт Пуассона матеріалу балки у поздовжньому та поперечному (зі штрихами) напрямах; $2 h, t-$ висота та ширина перерізу балки.

Вирази для напруження $\sigma_{x}$ та переміщень $W(x, \pm h)$ зовнішніх граней балки, відповідно до цієї моделі, мають вигляд:

$$
\begin{aligned}
& \sigma_{x}=\frac{M}{I} z+\frac{z}{I}\left(z^{2}-\frac{3}{5} h^{2}\right)\left[\left(\frac{E}{2 G^{\prime}}-v^{\prime \prime}\right) q_{2}-\frac{E}{E^{\prime}}\left(1-\frac{v^{\prime \prime} G^{\prime}}{E}\right) \frac{h^{2}}{4} q_{2}^{\prime \prime}\right] \\
& W(x, \pm h)=w(x) \pm\left(q^{+}-q^{-}\right) \frac{h}{2 E^{\prime}}+\frac{5 h \varepsilon_{0}}{16 E^{\prime}}\left(q^{+}+q^{-}\right)+\frac{h^{2}}{2} v^{\prime \prime} w^{\prime \prime}
\end{aligned}
$$

Розв'язок диференціального рівняння (1) визначає остаточний вигляд формул для напружень та переміщень кожної точки балки-смуги довжиною $2 L$, повинен задовольняти двом граничним умовам на кожному із країв смуги. 
Якщо ці краї $x= \pm L$ обперті на горизонталі $z=z_{0},\left(-h \leq z_{0} \leq h\right)$, то така умова має вигляд:

$$
M_{x}=0,\left.W\right|_{z=z_{0}}=0 .
$$

Початок координатних осей $O x$ i $O z$, котрі співпадають із середньою лінією балки-смуги і нормаллю до неї, знаходиться у центрі балки. Нижня поверхня балки $(z=h)$ послаблена крайовою тріщиною завглибшки $l$, що розміщена у розтягнутій зоні посередині нижньої поверхні балки (рис.1).

Якщо балка зверху $(z=-h)$ навантажена розподіленим навантаженням $q^{-}=q=$ const,$\left(q_{1}=-q / 2, q_{2}=q\right)$, то за граничних умов (3) розв' язок рівняння (1), дозволить отримати наступні формули:

$$
\begin{gathered}
\sigma_{x}=\frac{q z}{2 I}\left[\left(L^{2}-x^{2}\right)+\alpha^{2}\left(\frac{2}{3} z^{2}-\frac{2}{5} h^{2}\right)\right] ; \alpha^{2}=\frac{E}{2 G^{\prime}}-v^{\prime \prime} . \\
\sigma_{z}=\frac{q 1}{t}+\frac{q 2}{6 I}\left(3 h^{2}-z^{2}\right) z ; \quad \tau_{x z}=\frac{3 Q_{x}}{4 t h}\left(1-z^{2} / h^{2}\right) ; \\
U(x, z)=u(x)+z \cdot \gamma_{x}(x)-\frac{\varepsilon_{2} z}{6 I}\left(5 z^{2}-3 h^{2}\right) \frac{Q_{x}}{G^{\prime}} ; \\
W=\frac{q\left(L^{2}-x^{2}\right)}{24 E_{x} I}\left(5 L^{2}-x^{2}+12 \varepsilon_{1} h^{2}-6 v^{\prime \prime} z^{2}\right)+\frac{q\left(z_{0}-z\right)}{2 t E^{\prime}}+ \\
+\frac{v^{\prime \prime} \varepsilon_{1} q h^{2}}{2 E I}\left(z^{2}-z_{0}^{2}\right)+\frac{q}{E^{\prime} t h}\left[C_{1}-C_{2}\left(z^{2}+z_{0}^{2}\right) h^{2}\right]\left(z^{2}-z_{0}^{2}\right) . \\
C_{1}=\frac{3}{8}\left(\alpha_{z}+\frac{v^{\prime} E}{G^{\prime}}\right) ; C_{2}=\frac{1}{16}\left(\alpha_{z}+\frac{v^{\prime} E}{G^{\prime}}-v^{\prime} \cdot v^{\prime \prime}\right) .
\end{gathered}
$$

Для смуги прямокутного перерізу максимальні значення розтягувального напруження $\sigma_{x}^{*}$ спрощується до вигляду:

$$
\sigma_{x}^{*}=\frac{3}{4} \frac{q^{*} L^{2}}{h^{2}}\left(1+\frac{4 \alpha^{2}}{15} \frac{h^{2}}{L^{2}}\right)=\sigma_{\kappa л}^{\max } k_{\sigma},
$$

де $q^{*}=q / t ; \quad k_{\sigma}=1+\frac{4 \alpha^{2}}{15} \frac{h^{2}}{L^{2}}-$ коефіцієнт, що враховує вплив деформацій поперечного зсуву та обтиснення, а також поперечної анізотропії матеріалу. 
Поклавши у формулі (5) значення коефіцієнта $k_{\sigma} \equiv 1$, отримаємо результати класичної теорії балок Бернуллі-Ейлера.

За умови мализни довжини тріщини $l<<h, t$, та на основі розв'язку про тріщину на краю півплощини, задача знаходження критичного навантаження $q^{*}$ зводиться до розв'язування рівняння, що впливає із силового критерію Дж. Ірвіна [4]:

$$
K_{I}^{*}=K_{I C} ; \text { або } \sigma_{x}^{*}\left(q^{*}, h\right) \sqrt{\pi l} \cdot 1,12=K_{I C},
$$

де $K_{I C}$ - критичне значення коефіцієнта інтенсивності напружень (в'язкості руйнування), яке не залежить від розмірів та геометрії елемента конструкції; $\sigma_{x}^{*}\left(q^{*}, h\right)=\frac{3}{4} \frac{L^{2} q^{*}}{h^{2}} k_{\sigma}$ - нормальне напруження у волокні $(x=0, z=h)$ бруса, де розміщена тріщина.

На основі залежностей (5),(6) знаходимо граничне значення розподіленого навантаження $q_{K_{C}}^{*}$ для балки, пошкодженої тріщиною, довжиною $l$ :

$$
q_{K_{C}}^{*}=1,19 \frac{h^{2}}{L^{2} k_{\sigma}} \cdot \frac{K_{I C}}{\sqrt{\pi l}} .
$$

Одночасно, поряд із формулою (7), залежність для визначення граничного навантаження $q^{*}$ для балки без тріщини можна отримати 3 умови міцності за найбільшими нормальними напруженнями у вигляді:

$$
\sigma_{x}^{*}\left(q^{*}, h\right)=\sigma_{\text {мu. }}^{p} .
$$

Звідки $\quad q_{\sigma}^{*}=\frac{4}{3} \frac{h^{2}}{L^{2} k_{\sigma}} \sigma_{m u .}^{p}$,

де $\sigma_{\text {мu. }}^{p}$ - граничний опір матеріалу за розтягу.

У табл. 1. занесені дані підрахунків за формулами (7), (8) зведеного граничного навантаження $q_{i}^{*}$, де $\left(q_{i}^{*}=q_{\sigma}^{*}\right.$ та $\left.q_{i}^{*}=q_{K c}^{*}\right)$ для ізотропного матеріалу - сталь Ст.3, де $\sigma_{0,2}=200 \mathrm{MПа,} \mathrm{величина} \mathrm{граничного} \mathrm{КІН}$ $K_{I C}=22 \mathrm{MПа} \sqrt{M}, \quad$ а також композитного склопластику 27-63С 3 пружними характеристиками $E=28,8$ ГПа, $E^{\prime}=9,3$ ГПа, $G^{\prime}=3,1$ ГПа, $v^{\prime \prime}=0,32, \quad K_{I C}=27,1 \mathrm{MПа} \sqrt{M}, \sigma_{0,2} \approx \sigma_{m \mu .}^{p}=480$ МПа. Довжина тріщини приймалась рівною $l=1 c$ при різних відношеннях $L / h$. У знаменнику 
величини $q_{i}^{*}$ пораховані за формулою (8), коли тріщина відсутня . Дані в дужках пораховані за класичною теорією, коли коефіцієнт $k_{\sigma} \equiv 1$.

Таблиця 1

Значення зведеного граничного навантаження $q_{i}^{*}$

\begin{tabular}{|c|c|c|c|c|}
\hline \multirow{2}{*}{5} & \multicolumn{2}{|c|}{ Сталь Ст. 3 } & \multicolumn{2}{c|}{ Склопластик 27-63 С } \\
\cline { 2 - 5 } & $k_{\sigma}$ & $q_{i}^{*}(\mathrm{MПа})$ & $k_{\sigma}$ & $q_{i}^{*}$ (МПа) \\
\hline 5 & 1,011 & $\frac{5,844(5,91)}{10,55(10,67)}$ & 1,029 & $\frac{7,075(7,28)}{24,89(25,60)}$ \\
\hline 3 & 1,030 & $\frac{15,93(16,41)}{28,78(29,63)}$ & 1,079 & $\frac{18,72(20,21)}{65,88(70,11)}$ \\
\hline
\end{tabular}

Із аналізу даних табл. 1 видно, що граничні навантаження за класичною теорією балок, для кожної конкретної довжини, відрізняються від даних, одержаних згідно запропонованої теорії композитних балок, пропорційно до множника $k_{\sigma}$. Останні залежать фізичних характеристик матеріалу, а також відношень $L / h$.

Спираючись на формули (7), (8), у більш загальному випадку, можемо знайти коефіцієнт $n$ зниження граничного навантаження, за умови появи у балці тріщини, у вигляді:

$$
n=\frac{q_{\sigma}^{*}}{q_{K_{C}}^{*}}=\frac{1,12 \sqrt{\pi l} \cdot \sigma_{m u .}^{p} .}{K_{I C}} .
$$

Згідно формули (9), цей коефіцієнт для ізотропного матеріалу (сталь Ст. 3) дорівнює $n=1,81$, а для склопластика 27-63С він удвічі більший $n=3,52$. Такими ж за величиною будуть ці коефіцієнти і згідно класичної теорії Бернуллі - Ейлера.

Якщо ж у наведеній формулі межу тріщиностійкості $K_{I C}$ записати через критичне напруження $K_{I C}=\sigma_{\kappa p} \sqrt{\pi l}$, то коефіцієнт $n$ зниження граничного навантаження можна отримати у спрощеному та доступнішому вигляді - $n=1,12 \sigma_{\text {ми. }}^{p} / \sigma_{\kappa p}$. Без множника 1,12 (чисте відношення напружень $\left.\sigma_{m \mu .}^{p} / \sigma_{\kappa p}\right)$, цей коефіцієнт у роботі В.3. Партона та Є.М. Морозова [8] називається коефіцієнтом зниження міцності $\alpha$. Тут необхідно зауважити, що цей уточнювальний множник знайдений для півплощини, без урахування розмірів балки. Тому, щоб добитися кращого 
узагальнення формули (9) для коефіцієнта $n$, потрібно замість множника 1,12 (у чисельнику) застосувати так звану функцію форми та розмірів об'єкту - $Y(l / 2 h)$, яка залежить від відносної довжини тріщини, розмірів балки та виду навантаження. У такому випадку формула (9) зведеться до вигляду:

$$
n=\frac{q_{\sigma}^{*}}{q_{K_{C}}^{*}}=\frac{\sqrt{\pi l} \cdot \sigma_{m u .}^{p}}{K_{I C}} Y(l / 2 h) .
$$

Наприклад, у випадку чотириточкового згину балки із тріщиною у зоні розтягу ця функція має вигляд [3]:

$$
Y(l / 2 h)=1,12-1,12 \rho+3,74 \rho^{2}+3,87 \rho^{3}-19,05 \rho^{4} .
$$

Тут вважається, що $\rho=l / 2 h \leq 0,7$.

Аналогічні узагальнення для інших навантажень та об'єктів вимагають ширших як теоретичних, так і експериментальних досліджень.

Таким чином, визначивши коефіцієнт зниження навантаження $n$ i знаючи характеристики тріщиностійкості матеріалу, граничне навантаження для конструкційного елемента, пошкодженого тріщиною $q_{K_{C}}^{*}$ можна визначити через граничне навантаження $q_{\sigma}^{*}$ для елемента без тріщини за простою формулою $q_{K_{C}}^{*}=q_{\sigma}^{*} / n$.

Разом із тим, одержані аналітичні розрахунки все одно бажано піддавати експериментальній перевірці для конкретних випадків як навантаження, так і характеру пошкодження. Це пов'язано із тим, що коефіцієнти інтенсивності напружень $K_{i}$ шукаються у межах лінійної механіки руйнування.

\section{Висновки}

Досліджено вплив на залишкову міцність наявність у балках пошкоджень типу тріщин і поперечної анізотропії матеріалу, порівняно із результатами для балок без пошкоджень. Записано формули для критичних навантажень на конструкційні елементи пошкоджених тріщиною, які порівнюються із граничними навантаженнями для елементів без тріщини. Досліджено залежність цих навантажень від застосованої розрахункової моделі, що враховує наявність тріщини, а також механічних i фізичних характеристик елемента конструкції. Показано, що врахування у розрахунках ефектів впливу деформацій поперечного зсуву та обтиснення веде до зниження граничних навантажень для балки. Наведено числові результати для зведених граничних навантажень ізотропних і композитних балок різної довжини та дається їх аналіз. Отримано коефіцієнт зниження граничного навантаження $n$ у балках, пошкоджених тріщиною, за допомогою якого можна визначити залишкову міцність порівняно із розрахунковою. 


\section{References}

1. Serensen S.V., Zaytsev H.P. Nesushchaya sposobnost' tonkostennykh konstruktsiy yz armyrovannykh plastykov s defektamy. Kyev. Nauk. dumka. 1982. 296 p. [In Russsian]

2. Lozovoy B.L., Panasyuk V.V. Nekotorbe zadachy yzhyba polosy s pryamolyneynoy treshchynoy. Yz. AN SSSR. OTN. Mekhanyka y mashynostroenye. 1962. pp.138-143. [In Russsian]

3. Spravochnyk po koeffytsyentam yntensyvnosty napryazhenyy: V 2-kh tomakh. Per. s anhl. Pod red. Yu. Murakamy. M.: Myr, 1990. - 1016 p. [In Russsian]

4. Shvabyuk V.I., Rotko S.V., Uzhegova O.A. Bending of a Composite Beam with a Longitudinal Section. Strenght of Materials. 2014. Vol. 46. No.4, pp. 558-566.

5. Bozhydarnyk V.V., Shvab"yuk V.I. Z hyn kompozytnoyi balky z poperechnoyu trishchynoyu. Materialy I ukrayins'ko-pol's'koho naukovoho sympoziumu (L'viv-Shats'k, 14-19 veresnya 1995 roku). L'viv: Svit. 1995, pp. 6-9. [in Ukrainian]

6. Kit H.S., Sushko O.P., Lozovyy B.L. Z hyn balok z kruhovymy trishchynamy. Mashynoznavstvo, 2007. No 2(116), pp. 9-13. [in Ukrainian]

7. Sulym H.T., Opanasovych V.K., Slobodyan M.V., Bilash O.V. Chystyy z'hyn balky $\mathrm{z}$ trishchynoyu $\mathrm{z}$ urakhuvannyam plastychnykh smuh bilya yiyi vershyny. Matematychni problemy mekhaniky neodnoridnykh struktur. Za zah. red. R.M. Kushnira i H.S. Kita. L'viv: IPPM im. Ya.S. Pidstryhacha NANU. 2019. V.5, pp. 206-207. [in Ukrainian]

8. Parton V.Z., Morozov E.M. Mekhanyka upruhoplastycheskoho razrushenyya. M.: Nauka. Hlavnaya redaktsyya fyz.-mat. lyt. 1985. 504 p. [In Russsian]

\section{Список використаної літератури}

1. Серенсен С.В., Зайцев Г.П. Несущая способность тонкостенных конструкцій из армированных пластиков с дефектами. Киев. Наук. думка. 1982. $296 \mathrm{c}$.

2. Лозовой Б.Л., Панасюк В.В. Некоторые задачи изгиба полосы с прямолинейной трещиной. Из. АН СССР. ОТН. Механика и машиностроение. 1962. C.138-143.

3.Справочник по коэффициентам интенсивности напряжений: В 2-х томах. Пер. с англ. Под ред. Ю. Мураками. М.: Мир, 1990. 1016 с.

4. Shvabyuk V.I., Rotko S.V., Uzhegova O.A. Bending of a Composite Beam with a Longitudinal Section. Strenght of Materials. 2014. Vol. 46. No.4. P. 558-566.

5. Божидарник В.В., Шваб'юк В.І. Згин композитної балки 3 поперечною тріщиною. Матеріали I українсько-польського наукового симпозіуму (ЛьвівШацьк, 14-19 вересня 1995 року). Львів: Світ. 1995. С. 6-9.

6. Кіт Г.С., Сушко О.П., Лозовиий Б.Л. Згин балок з круговими тріщинами. Машинознавство, 2007. №2(116). С, 9-13.

7. Сулим Г.Т., Опанасович В.К., Слободян М.В., Білаш О.В. Чистий згин балки 3 тріщиною з урахуванням пластичних смуг біля іï вершини. Математичні проблеми механіки неоднорідних структур. За заг. ред. Р.М. Кушніра і Г.С. Кіта. Львів: ІППМ ім. Я.С. Підстригача НАНУ. 2019. В.5. С. 206-207.

8. Партон В.3., Морозов Е.М. Механика упругопластического разрушения. М.: Наука. Главная редакция физ.-мат. лит.-ры. 1985. - 504c. 